\title{
Anatomical Traits as an Additional Taxonomic Tool for Munronia pinnata (Wall.) Theob. (Meliaceae) Found in Sri Lanka
}

\author{
R.M. Dharmadasa ${ }^{1, *}$, P.L. Hettiarachchi ${ }^{2}$, GAS Premakumara ${ }^{1}$ \\ ${ }^{1}$ Industrial Technology Institute, Bauddhaloka Mawatha, Colombo, Sri Lanka \\ ${ }^{2}$ Faculty of Applied Sciences, Rajarata University Mihinthale, Anuradhapura, Sri Lanka \\ *Corresponding author: dharma@iti.lk, dharmadasarm@gmail.com
}

Received June 19, 2014; Revised June 28, 2014; Accepted July 02, 2014

\begin{abstract}
Munronia pinnata (Wall) Theob. (Meliaceae) is a rare, therapeutically important medicinal plant widely used in traditional systems of medicine in Sri Lanka. Different populations of M. pinnata in Sri Lanka display an array of variable phenotypic characters. However, due to seasonal variations and rare flowering, study of reproductive characters in all populations is not possible. The present study emphasizes on the use of anatomical characters of leaf, stem and petiole of 13 populations of $M$. Pinnata as a systematic tool. Six monomorphic and 53 polymorphic quantitative and qualitative anatomical characters were scored. Cluster analysis was performed to derive the taxonomic relationship among the populations studied. A single access, indented key which could be used to identify anatomically different populations of $M$. pinnata was constructed using taxonomically stable anatomical characters. Populations collected from Ritigala reserve possessed distinguished characters such as presence of extra vascular bundles in outer part of the main vascular bundle in the midrib, higher number of epidermal cells in the upper epidermis, four separated parts in the stem vascular bundle and absence of secretory cells in the pith. Therefore, reconsideration of its taxonomic status is suggested. However, the level of taxon has to be decided after numerical analysis of combined taxonomic evidence of different disciplines. This study demonstrates that the importance of anatomical traits as an additional taxonomic tool for correct identification of M. pinnata.
\end{abstract}

Keywords: anatomy, Munronia pinnata, Meliaceae, Medicinal plant, taxonomic tool

Cite This Article: R.M. Dharmadasa, P.L. Hettiarachchi, and Premakumara S, "Anatomical Traits as an Additional Taxonomic Tool for Munronia pinnata (Wall.) Theob. (Meliaceae) Found in Sri Lanka." World Journal of Agricultural Research, vol. 2, no. 4 (2014): 142-150. doi: 10.12691/wjar-2-4-1.

\section{Introduction}

Munronia pinnata (Wall.) Theob. (Meliaceae) is a therapeutically important, rare medicinal plant species with an array of variable phenotypic characters (3, 5, 7, 9 and 11 leaflets types). It is distributed in many parts of Sri Lanka which is found up to 900 meters from the mean sea level $[1,2,3]$. Although $M$. pinnata populations are variable in their phenotype [means of number of leaflets per leaf (3, 5, 7, 9, 11 leaflets) and other morphological features identification of intraspecific taxa is not possible due to inadequacy of data ${ }^{[1]}$. For example, a study of $M$. pinnata across different agro-ecological regions in Sri Lanka found that there were 16 different phenotypes. However, the study of reproductive characters in all populations was not possible due to seasonal and rare flowering of some populations [4,5]. In contrast, the study of plant anatomy greatly helps to identify herbarium specimens which do not have flowers and fruits [6]. Additionally, the anatomy of different parts/ organs (features of cuticle epidermis, stomata, subsidiary cells and trichomes etc.) of plant species have been studied as a tool for systematic identification of certain taxa $[7,8,9,10,11]$. Therefore, investigation of taxonomically important anatomical traits as an additional taxonomic tool for correct identification of existing morphotypes of $M$. pinnata is timely and important in order to delimit ambiguity.

\section{Materials and Methods}

\subsection{Plant Materials}

Thirteen $M$. pinnata populations collected from different climatic zones in Sri Lanka were identified by comparing with authentic herbarium specimens available at Royal Botanical Garden, Peradeniya, Sri Lanka. Voucher specimens (HTS1 - HTS13) were prepared and deposited in the institutional Herbarium. In order to minimize the environmental impact all plants were potted in a similar mixture of soil (sand: topsoil: compost $=1: 1: 2$ ) found in their natural habitat and acclimatized under uniform greenhouse conditions (normal daylight and day length, temperature around $30^{\circ} \mathrm{C}$ ) for five years before taking samples. Details of these populations are presented in Table 1. 
Table 1. Details of the localities of the thirteen populations of Munronia pinnata used for the study

\begin{tabular}{|c|c|c|c|c|c|c|}
\hline Population code & Locality & District & Number of Leaflets & Altitude (M) & Agro- climatic zone & Rainfall (mm) \\
\hline APRG-5 & Ritigala & Anuradhapura & 5 & 396 & DL-3 & $1000-1500$ \\
\hline BDHM-3 & Haldummulla & Badulla & 3 & 960 & IU-1 & $2000-2500$ \\
\hline GPPW-3 & Pallewela & Gampaha & 3 & 35 & WL-1 & $3500-4000$ \\
\hline GPWP-3 & Warakapola & Gampaha & 3 & 125 & WL-1 & $3500-4000$ \\
\hline KGKP-5 & Kuliyapitiya & Kurunegala & 5 & 30 & DL-1 & $1500-2000$ \\
\hline MGMD-3 & Madulla & Moneragala & 3 & 196 & IL-1 & $2500-3000$ \\
\hline MGMG-9/11 & Srivijayapura & Moneragala & $9 / 11$ & 220 & IL-1 & $2500-3000$ \\
\hline MGNG-3 & Nilgala & Moneragala & 3 & 283 & IL2 & $2500-3000$ \\
\hline MGWW-7 & Wellawaya & Moneragala & 7 & 192 & IL-1 & $1500-2000$ \\
\hline MTMM-5/7 & Meemure & Matale & $5 / 7$ & 420 & WM-2 & $2000-2500$ \\
\hline MTNU-5 & Naula & Matale & 5 & 375 & WM-2 & $2000-2500$ \\
\hline NEMR--3 & Mathurata & Nuwaraeliya & 3 & 1050 & WU & $3000-3500$ \\
\hline
\end{tabular}

DL- Low country dry zone; IU- Up country intermediate zone; WL- Low country wet zone; IL- Low country intermediate zone; WM-Mid country wet zone; WU-Up country wet zone.

\subsection{Preparation of Temporary Mounts}

Representative samples (20 plants per population) of stem, petiole and leaf were obtained from approximately the same aged, healthy, well acclimatized plants. Free hand transverse sections were made using a razor blade and taken through an alcohol series (as 30\% and 50\% alcohol for 5 minutes each). The samples were subsequently stained with $1 \%$ safranin in 50\% ethanol. Stained material was mounted on glass slides using glycerin and Photomicrographs were taken.

\subsection{Determination of the Stomatal Index}

Determination of stomatal index was carried out as per literature [12]. Approximately $5 \mathrm{~mm}$ leaf pieces were warmed up in saturated chloral hydrate solution until they became transparent. These were made into temporary mounts as described above. Number of epidermal cells and stomata present in microscopic fields were counted and recorded under x40 magnification. Stomatal index per sample was calculated using the formula given below.

$$
I=\frac{S \times 100}{E+S}
$$

Where $\mathrm{S}=$ number of stomata per unit area, $\mathrm{E}=$ number of ordinary epidermal cells in the same unit area. For each leaf sample, no fewer than ten determinations were carried out and finally the average value for each population was worked out.

\subsection{Statistical Analysis}

The measured anatomical traits across 13 populations of $M$. pinnata were analyzed using PCORD ver. 4 (Oregon, USA). A total of 59 anatomical features of leaf, petiole, stem and epidermal peels of upper and lower surfaces were recorded. The variation observed in each character was divided into two or more character states and each was ranked with a numerical value. These were recorded in all samples. Using these numerical values, a data table for cluster analysis was prepared. When intra populational variation was absent for a given character, data of all ten individuals of that population was considered as a single value to prepare the final data table for analysis and clusters generated were used to derive the taxonomic relationship among populations studied.

\section{Results and Discussions}

In the present study, taxonomically important anatomical characters of leaf, stem and petiole of 13 populations of $M$. Pinnata were investigated as a systematic tool. Six monomorphic and 53 polymorphic quantitative and qualitative anatomical characters were scored. Since the study was carried out using plants acclimatized under uniform environmental conditions, the anatomical features recorded in the present study could be considered as a true reflection of their genetic make-up. Polymorphic characters with their character status together with data table prepared for cluster analysis are given in Table 2. The cluster generated by using 53 polymorphic characters of 13 populations of $M$. pinnata is given in Figure 1. Distinguished anatomical features of different parts of the plants are presented in Plates 1-5.

Out of the 59 anatomical characters recorded 6 are monomorphic and hence seem species specific. Monomorphic characters such as single palisade layer, anomocytic stomata, and the presence of stone cell layers could be used to identify all $M$. pinnata populations. At least some of the polymorphic characters such as presence of secondary vascular bundles in the stem, glandular sessile and stalked trichomes in the epidermis, presence or absence of sand crystals, number of parenchyma and collenchyma cell layers in the stem and stone cell layers could be used to differenciate $M$. pinnata populations.

\subsection{Leaf Midrib Anatomy}

As shown in Plates 1 the lower outer surface of midrib transverse sections of 9 populations was even while in 3 populations it was uneven and one population was slightly uneven. Diversity of simple unicellular, bifurcate, glandular sessile and glandular stalked trichomes as well as difference in their frequency of occurrence was observed. 
Table 2. List of anatomical characters together with their character states recorded in 13 populations of Munronia pinnata used for the present study

\begin{tabular}{|c|c|}
\hline Plant character & Nature of the character \\
\hline \multicolumn{2}{|l|}{ A. Terminal (distal) leaflet } \\
\hline 1. Outer surface & Even (1), Uneven (2), Slightly uneven (3) \\
\hline 2. Upper epidermis & :Blunt projection (1), Sharp projection (2) \\
\hline 3. Lower epidermis & $\begin{array}{l}\text { :Circular slightly uneven (1), Boat shape slightly uneven (2), Boat shape uneven (3), Circular } \\
\text { even (4), }\end{array}$ \\
\hline 4. Trichome frequency & $\begin{array}{l}\text { : Few, both sides (1), Few, unicellular underside (2), Many, underside (3), Very few, unicellular } \\
\text { undersides (4), Few unicellular \& glandular in underside (5), Few unicellular \& glandular in both } \\
\text { sides (6) }\end{array}$ \\
\hline 5. Glandular trichomes & :Present (1), Absent (2) \\
\hline 6. Parenchyma cell layers & : 6-7 (1), 8-10 (2), 11-12 (3) \\
\hline 7. Collenchyma cell layers (Underside) & : 1-2 (1), 3-5 (2) \\
\hline 8. Palisade & :Single layer (1) \\
\hline 9. Palisade ratio & $: 2(1)$ \\
\hline 10. Vascular tissue & $\begin{array}{l}\text { : Two parts, crescent like part and smaller circular part (1), Two Crescent like parts separated } \\
\text { from few layers of parenchyma cells (2), Single crescent like lower part only (3), Single crescent } \\
\text { like part interrupted (3); Crescent like part and 1-2 adaxial parts (4), Lower crescent like part and } \\
\text { several adaxial parts (5) }\end{array}$ \\
\hline 11. Subsidiary vascular bundle/s & : Present (1), Absent (2) \\
\hline 12. Sclerenchyma & : As a few bundle in projection region (1), Few in the projected region (2), Very few (3) \\
\hline 13. Rosette crystals in the phloem & $\begin{array}{l}\text { : Few crystals in parenchyma (1), Many crystals in parenchyma (2), Few near vascular bundle } \\
\text { (3), Rare (4), Absent (5) }\end{array}$ \\
\hline 14. Green oïl like droplets & : Many in parenchyma (1), Few in parenchyma (2),Very few in parenchyma (3) \\
\hline 15. Abundance of secretary cavities in the phloem & : Many (1), Few in parenchyma cells (2), Rare (3), Very Rare (4) \\
\hline 16. Stone cell layer & : Present (1), Absent (2) \\
\hline 17. Inclusions in inter cellular space & : Many among parenchyma cells (1), Few among parenchyma cells (2), Absent (3) \\
\hline \multicolumn{2}{|l|}{ B. STEM CHARACTERS } \\
\hline 18. Cork & : Present (1), Absent (2) \\
\hline 19. Outer shape & : Round (1), Oval (2), Irregular (3) \\
\hline 20. Trichome & : Present (1), Absent (2) \\
\hline 21. Trichome frequency & : Many (1), Few (2), Very few (3) \\
\hline 22. Vascular bundle shape & : Oval (1), Triangular (2); Irregular (3) \\
\hline 23. Vascular bundle nature & : Complete (1), Incomplete (2), Incomplete 5 parts (3), \\
\hline 24. Vascular bundle thickness & : Thick (1), Medium (2), Thin (3) \\
\hline 25. Subsidiary vascular bundles & : Present (1), Present many (2); Absent (3) \\
\hline 26. Pith shape & : Oval (1), Circular (2), Crown shaped (3), Star shaped (4), Triangular (5), Irregular (6) \\
\hline 27. Pith size & : Small(1), Medium (2), Large (3) \\
\hline 28. Secretary cells in the pith & : Many (1), Few (2), Very few (3) \\
\hline 29. Druses & : Present (1), Absent (2) \\
\hline 30. Cell inclusions & : Present (1), Absent (2) \\
\hline 31. Xylem:phloem ratio & : Unequal (1) \\
\hline \multicolumn{2}{|l|}{ C. PETIOLE CHARACTERS } \\
\hline 32. Outer shape & : Round (1), Triangular (2); \\
\hline 33. Outer surface & : Even (1), Slightly uneven (2), Uneven (3) \\
\hline 34. Unicellular trichomes & : Many (1), Few (2), Very few (3) \\
\hline 35. Glandular trichomes & : many (1), Few (2); Absent (3) \\
\hline 36. Parenchyma cell layers & : 7-8 (1), 9-10 (2), 11-12 (3), 13-14 (4) \\
\hline 37. Collenchyma cell layers (underside) & : 1-3 (1), More than 3(2) \\
\hline 38. Vascular bundle shape & : Triangular (1), Heart shape (2) \\
\hline 39. Vascular bundle nature & : Complete (1), Incomplete (2) \\
\hline 40. Vascular bundle thickness & : Thick(1), Thin (2) \\
\hline 41. Pith shape & : Triangular (1), Oval (2), Heart shape (3), \\
\hline 42. Pith size & : Small(1), Medium (2), Large (3) \\
\hline 43. Secretary cavities in the pith & : Present (1), Absent (2) \\
\hline 44. Cell inclusions & : Present (1), Absent (2) \\
\hline 45. Druses & : Present (1), Absent (2) \\
\hline X46. ylem: phloem ratio & : Unequal (1), Equal (2) \\
\hline \multicolumn{2}{|c|}{ D. LOWER EPIDERMIS LAMINAR (TERMINAL LEAF) } \\
\hline 47. Nature of the leaf & : Brittle (1), leathery nature (2) \\
\hline 48. Stomatal type & : Anomocytic \\
\hline 49. Glandular sessile trichome & : Present (1), Absent (2) \\
\hline 50. Glandular stalked trichome & : Present (1), Absent (2) \\
\hline 51. Epidermal cell margin & : Wavy (1), Moderately wavy (2), Entire (3) \\
\hline 52. Stomatal index & : Less than 6 (1), $6-7$ (2), >7 (3) \\
\hline 53. Shape of the epidermal cell & : Irregular (1), Hexagonal (2) \\
\hline \multicolumn{2}{|c|}{ E. UPPER EPIDERMIS LAMINAR (TERMINAL LEAF) } \\
\hline 54. Shape of the epidermal cell & : Irregular (1), Hexagonal (2) \\
\hline 55. No. of cells/field & : 250-300 (1), 301-350 (2), >350 (3) \\
\hline 56. Stomata * & : Present (1), Absent (2) \\
\hline 57. Glandular stalk trichome & : Present (1), Absent (2) \\
\hline 58. Epidermal cell margin & : Wavy (1), Moderately wavy (2), Entire (3) \\
\hline 59. Sandy crystals & : Present (1), Absent (2) \\
\hline
\end{tabular}




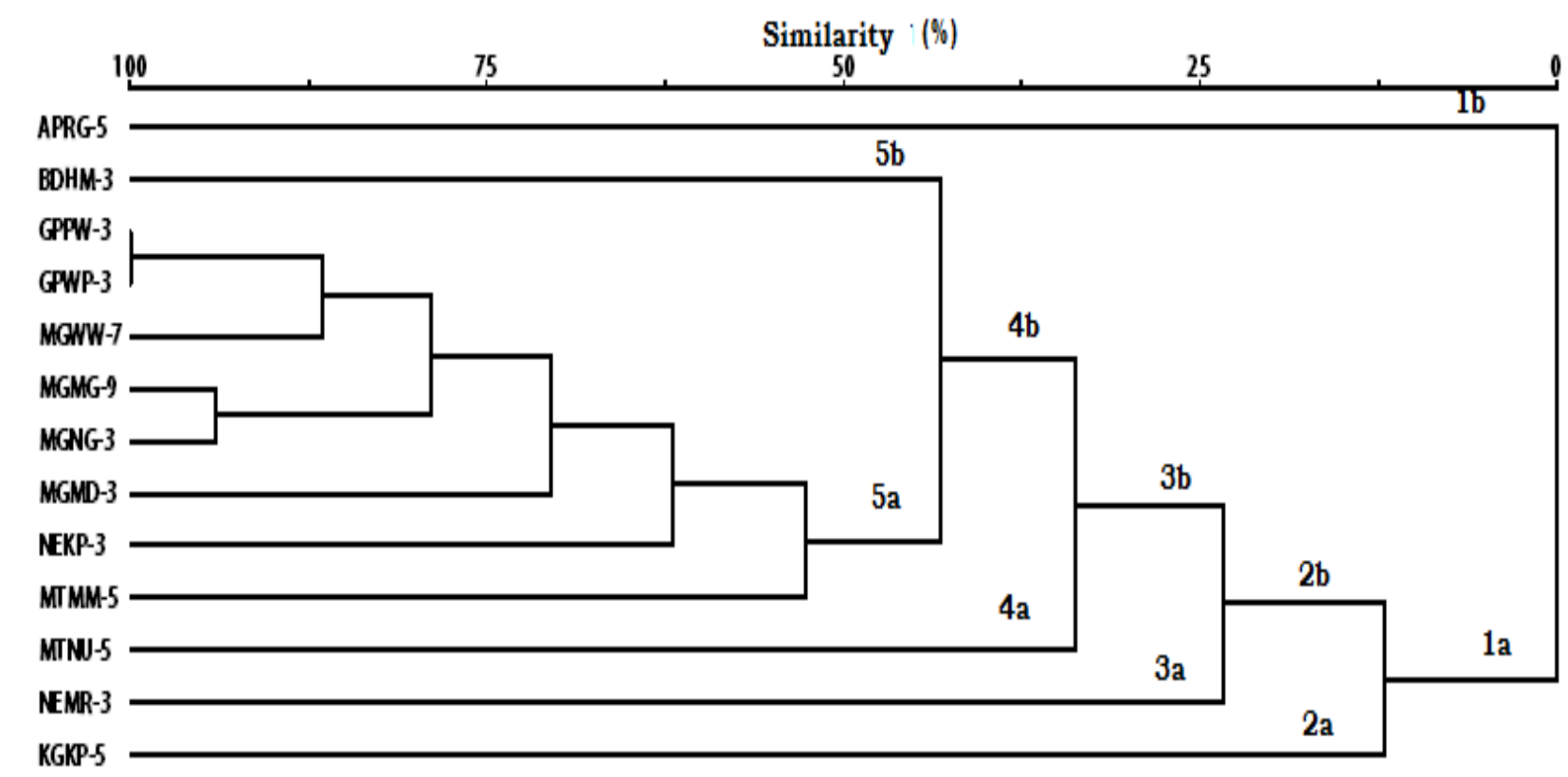

Figure 1. Dendrogramme generated by combining 53 polymorphic anatomical characters of 13 populations of Munronia pinnata
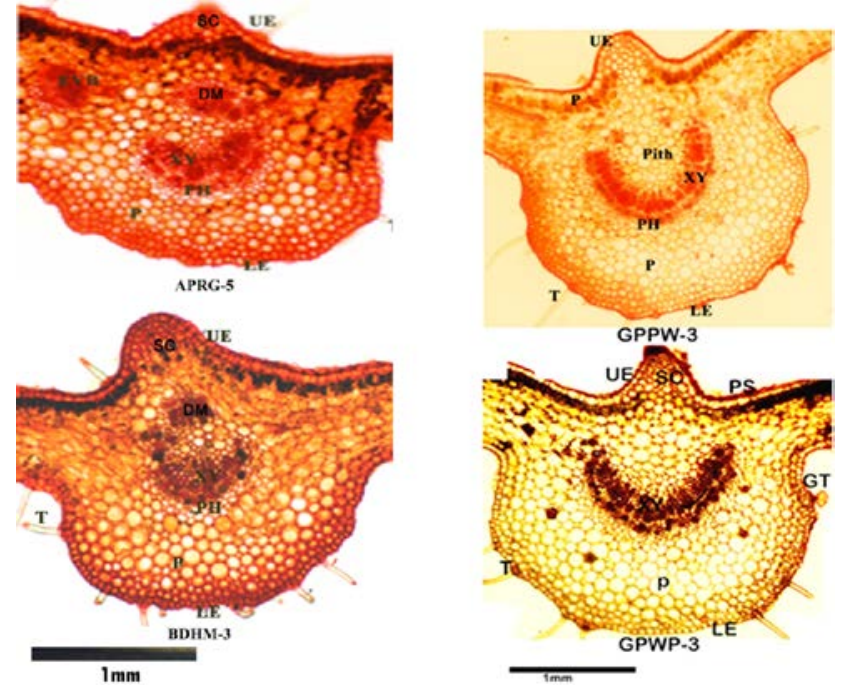

Plate 1. Representative leaf midrib transverse sections of populations of Munronia pinnata collected from Anuradhapura (APRG-5), Haldummulla (BDHM-3) Warakapola (GPWP-3) and Pallewela (GPPW3) [UE-Upper epidermis; SC- Sclerenchyma; DM- Daughter myristale; XY- Xylem; PH- Phloem; P-parenchyma; LE-Lower epidermis; TTrichome]

However, glandular type trichomes were observed only in populations GPPW-3, GPWP-3, MGMD-3MTMM-5 and MTNU-5. The adaxial surface has a sharp projection in 4 populations (BDHM-3, GPPW-3, GPWP-3 and MGMD-3), while there is the blunt projection in rest of the populations. Shape of lower surface was even or smooth, circular in 2 populations (GPPW-3, GPWP-3 and NEMR-3), circular, slightly uneven in 3 populations, (APRG-5, BDHM-3 and KGKP-5), boat shaped, slightly uneven in 3 populations (MGMG-9, MGNG-3, NEKP-3) and boat shaped prominently uneven in 4 populations (MGMD-3, MGWW-7, MTMM-5 and MTNU-5). Fewer number of parenchyma cell layers (5-6) underside the midrib was observed in APRG-5, MGMD-3, MTMM-5 AND NEMR-3 populations, while a higher number of parenchyma cell layers (11-13) in that area was observed only in GPPW-3 and GPWP-3 populations. The rest of the populations possessed a medium number (8-10) of parenchyma cell layers. Underneath the epidermis, a lesser number of collenchyma cell layers were observed in populations BDHM-3 AND NEMR-3 while rest of the populations possessed 3-5 collenchyma cell layers. Shape and size of the vascular bundles varied in different populations. Vascular bundle of MGMD-3, KGKP-5, MTNU-5 AND NEKP-3 consisted of two crescents like parts separated from few layers of parenchyma cells, while only a single crescent like lower part was observed in GPWP-3 \& GPPW-3 populations. Extra vascular bundles in outer part of the main vascular bundle were observed in APRG-5 population. Many Rosette crystals in the phloem were observed in MGWW-7 and NEKP-3, while they were rare in KGKP-5, MGNG-3 AND NEMR3 populations. Further, no rosette crystals were observed in GPPW-3, GPWP-3, and MGMG-9 and MGMM-5 populations.

Unidentified, darkly stained substance was observed in intercellular space of pith and cortex in NEKP-3 GPWP-3 MGWW-7 APRG-5 and MGNG-3 populations. Although all populations consisted of layer of stone cells, continuous layer of stone cells at the margin of the vascular region was observed in BDHM-3, NEKP-3, MTMM-5/7, MGMG-9/11 and MGNG-3 populations while rest of the populations it was discontinuous.

Characters such as the presence of unicellular, multicellular and glandular trichomes with varying shapes, single layer of palisade and difference in vascular bundle shape have been described as common characters for family Meliaceae by previous workers [13]. In this study, we also have observed distinct interpopulational variation in these characters among many other polymorphic characters in $M$. pinnata collected from different localities of Sri Lanka.

\subsection{Stem Anatomy}

Represent transverse sections taken from the stems of 13 populations of $M$. pinnata are presented in Plate 3. Shape of the stem varies from round (BDHM-3, GPWP-3, MGWW-7 GPPW-3) to irregular (KGKP-5, MGNG-3, APRG-5 MTMM-5/7, MTNU-5 \&APRG-5) and to oval (MGMD-3 \& NEKP-3) in different populations. The 
epidermis composed of few layers of rectangular cells covered with unicellular, bifurcate trichomes in varying frequency in different populations. Underneath the epidermis, the cortex composed with many layers of parenchyma. The vascular bundle shape was oval in BDHM-3, MGMD-3, GPWP-3, and MGWW-7 and NEKP-3 populations while it was irregular in rest of the populations. Further, complete vascular bundles were found in all populations bearing 3 leaflets except population MGNG-3, while incomplete vascular bundles were found in populations bearing more than 3 leaflets except population MGWW-7. In addition to the main vascular bundle, extra vascular bundles were found in cortex region of some populations (KGKP-5, MGMG-9, MGNG-3, MTMM-5, and NEMR-3) irrespective of their leaflet number. The pith size varies from small to large consisting of hexagonal or orbicular parenchymatic cells. Diverse pith shapes such as oval (KGKP-5 and NEMR-3), crown shape (MGMD-3, MGMG-9, MGWW-7 and NEKP-3), round (BDHM-3 and GPPW-3), triangular (MTMM-5), and irregular (APRG-5, GPWP-3, MGNG-3 and MTNU-5) were observed (Plates 3). In addition, diverse types of secretary cells, druses and cell inclusions were also present in varying frequencies. Previous studies demonstrated [14], that the cork of the stem of members in family Meliaceae has invariably arisen from the sub epidermis and consists of parenchyma cells in varying thickness. Moreover, the phloem and xylem constitute closed cylinders. Pith varies in sizes and presence of secretary cells and stone cells is common. Some of the observations of the present study are in accordance with this general description of family Meliaceae. However, according to the present observations, xylem and phloem (vascular bundle) of APRG-5, KGKP-5, MGMG-9, MGNG-3, MTMM-5 and MTNU-5 populations are not closed and shapes also vary, especially the vascular bundles of populations APRG-5, KGKP-5 are separated into many parts (Plates 3).
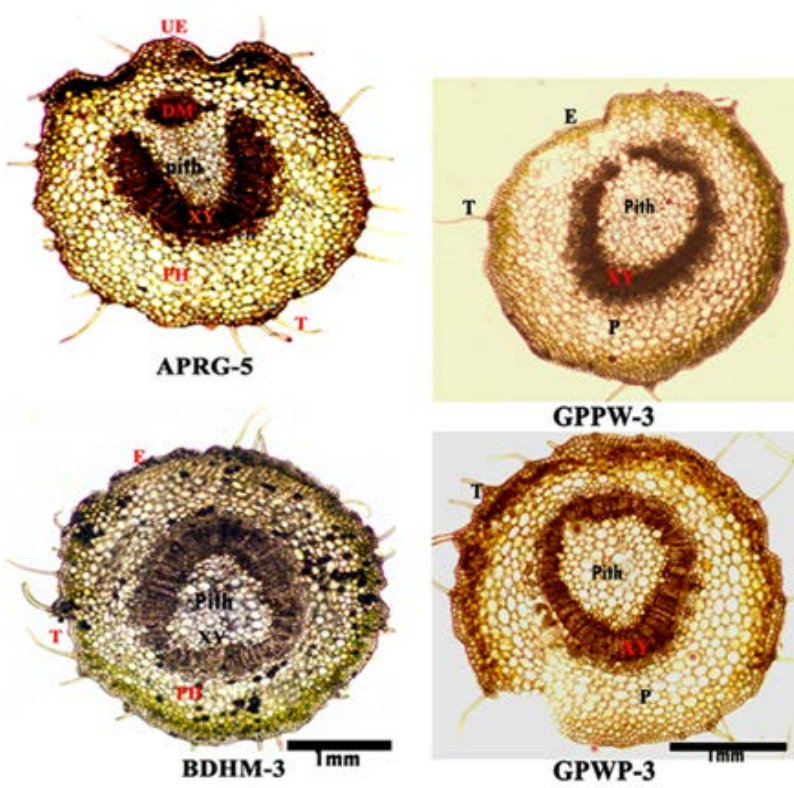

Plate 2. Representative petiole transverse sections of populations of Munronia pinnata collected from Anuradhapura (APRG-5), Haldummulla (BDHM-3) Warakapola (GPWP-3) and Pallewela (GPPW3) [UE-Upper epidermis; SC- Sclerenchyma; DM- Daughter myristale; XY- Xylem; PH- Phloem; P-Parenchyma; T-Trichome]
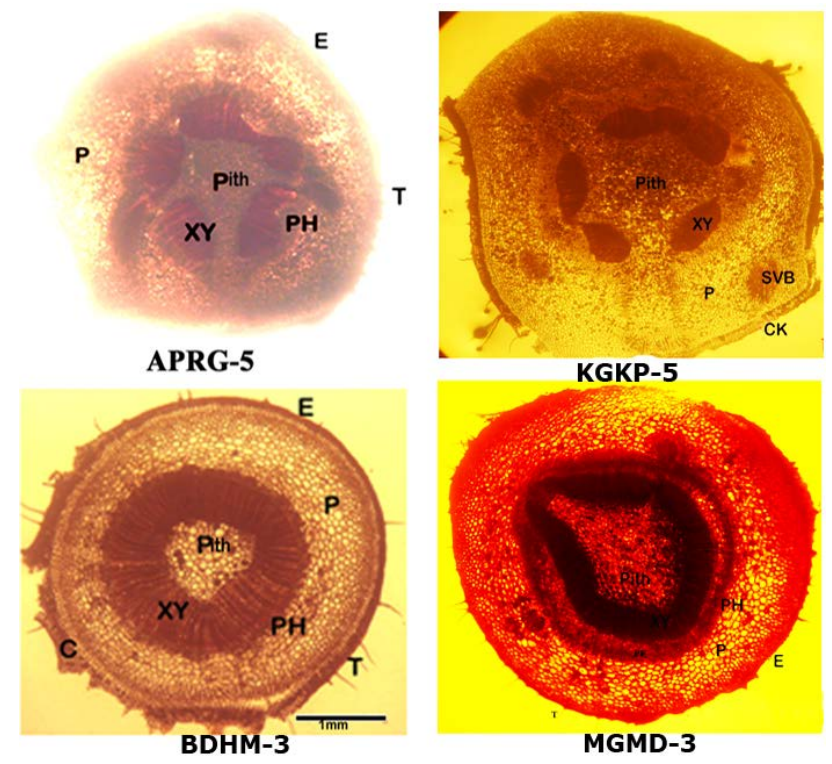

Plate 3. Representative stem transverse sections of populations of Munronia pinnata collected from Anuradhapura (APRG-5), Haldummulla (BDHM-3) Kuliyapitiya (KGKP-5) and Madulla (MGMD3) [UE-Upper epidermis; SC- Sclerenchyma; DM- Daughter myristale; XY- Xylem; PH- Phloem; P-parenchyma; LE-Lower epidermis; TTrichome]

\subsection{Petiole Anatomy}

As shown in Plate 2, the outer shape of the petiole was oval in APRG-5, KGKP-5, MGMD-3, MTMM-5, MTNU5 and NEMR-3 while rest of the populations possessed round outer shaped petioles. Outer surface of the petiole of population MTMM-5 was even while all others were slightly uneven to uneven in nature. Non glandular trichomes were present in all populations, but in varying frequencies. However, glandular trichomes were absent in GPWP-3 MGMM-9, MTMM-5 WW-7, MTNU-5 and NEMR-3 populations. Adaxial and abaxial epidermal cells of petiole of all populations were approximately equal in size. One to three layers of collenchyma cells were located immediately under the epidermis which is followed by 7-8 layers of parenchyma in GPWP-3 and MGNG-3 and 1112 layers in APRG-5, KGKP-5, and MTNU-5 while rest of the populations contained 9-10 layers of parenchyma. However, population MTMM-5 possessed a fairly thick parenchyma (13-14 layers).

Heart shaped complete vascular bundle was present in MGMG-9, MGNG-3 and MTMM-5 MGWW7 populations while, GPPW-3, NEMR-3 possessed triangular incomplete vascular bundles. Rest of the populations contained complete oval shaped vascular bundles. Presence of secretary cells, intercellular inclusions and druses were also observed. Presence of cylindrical or single crescent shaped vascular bundle, various types and sizes of secretary cells and solitary/ clustered crystals have been described as common characters of petiole of family Meliaceae [14]. They have clearly pointed out the necessity of considering further anatomical evidence to verify taxonomic divisions in family Meliaceae. In addition to the common features, a very clear variation in the vascular region such as the presence of triangular incomplete vascular bundle in NEMR-3, MTMM-5/7 and GPPW-3; triangular complete heart shaped vascular bundle in MGNG-3 and MGWW-7 
populations, a lower crescent like arch with adaxial circular part separated from few layers of parenchyma in GPPW-3 population were noted in this study.

\subsection{Structure of Lower and Upper Epidermis of End Leaf Lamina}

Shape of the epidermal cells of lower epidermis in population MGMD-3 was hexagonal with entire margin (Plate 4) while in all others epidermal cells were spherical with an irregular margin. Epidermal cell number per unit area was much higher in APRG-5 (Plate 5) than that in the other populations. Moreover, sandy crystals were present only in population NEMR-3.
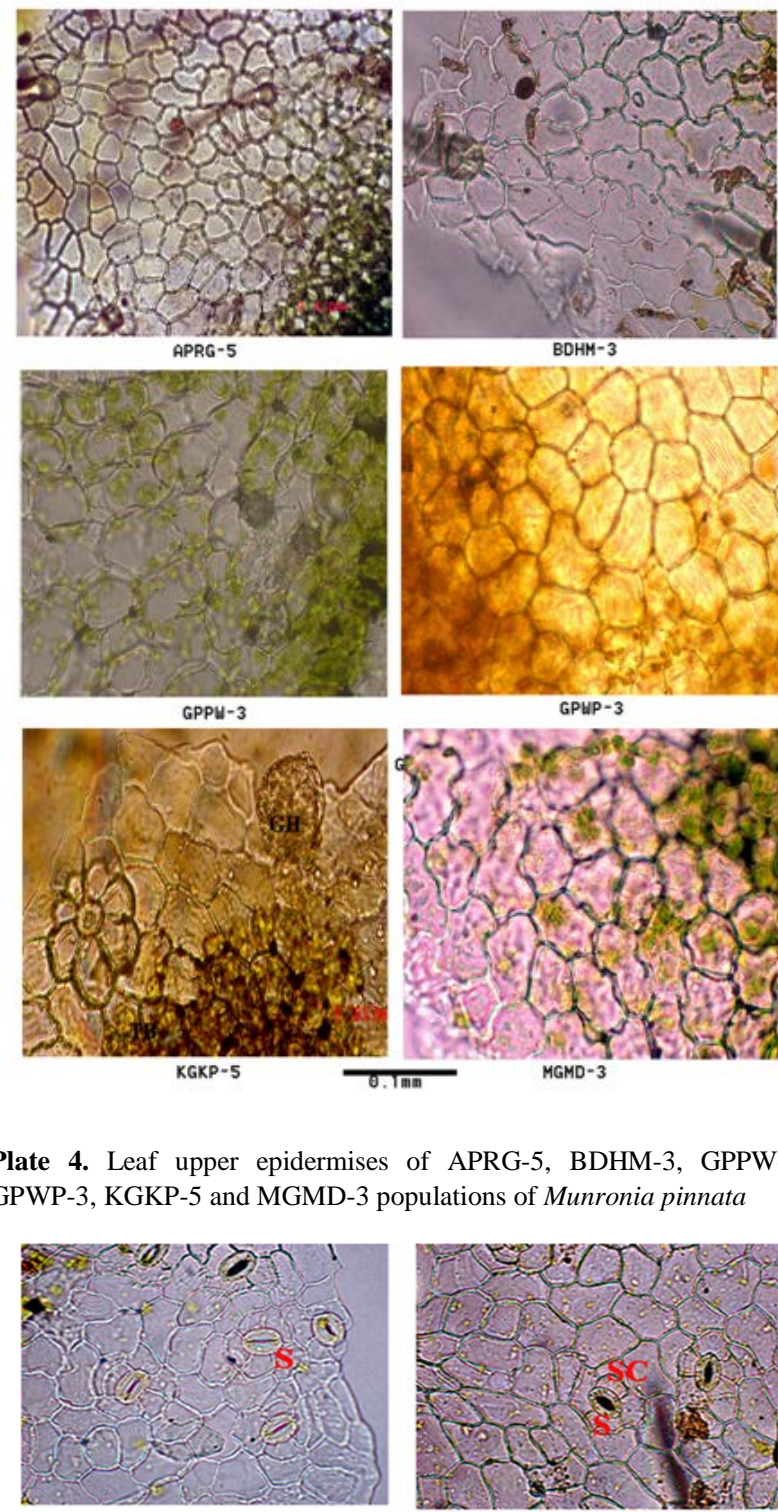

APRG -5

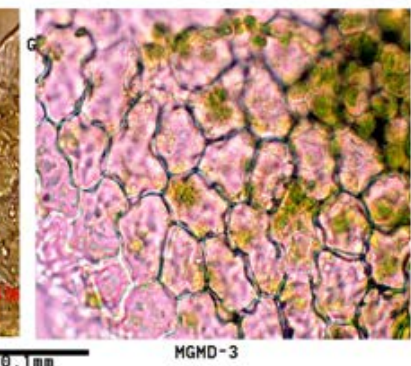

Plate 4. Leaf upper epidermises of APRG-5, BDHM-3, GPPW-3, GPWP-3, KGKP-5 and MGMD-3 populations of Munronia pinnata

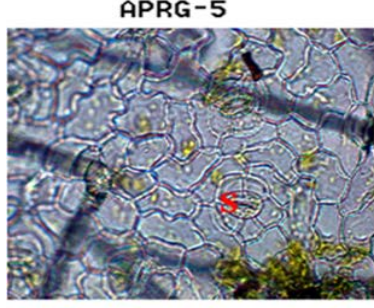

GPPW-3

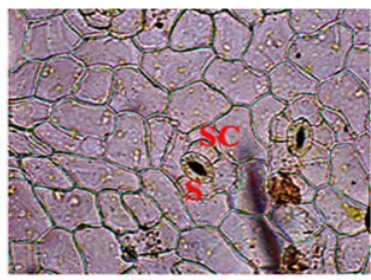

BDHM-3

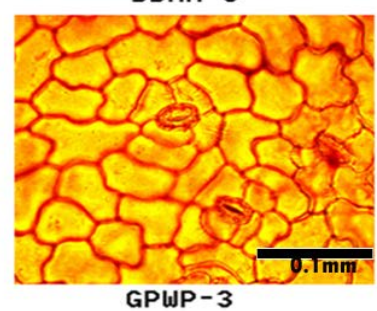

Plate 5. Leaf lower epidermis of APRG-5, BDHM-3, GPPW-3 and GPWP-3 populations of Munronia pinnata
The outer surface of the midrib in 6 populations was even while in 7 populations it was uneven. Diversity in epidermal trichomes (simple unicellular, bifurcate, glandular sessile and glandular stalked trichomes) in different frequencies was observed. However glandular type trichomes were observed only in GPPW-3, GPWP-3, NEMR-3, MTMM-5/7, APRG-5, MTNU-5 \& MGNG-3 populations. The upper portion has a sharp projection in 3 populations (BDHM-3, MGMD-3 \& GPPW-3), while there is a blunt projection in rest of the populations. Shape of lower epidermis was even circular shaped in 2 populations (NEMR-3 \& GPWP-3), circular slightly uneven in 4 populations, (BDHM-3, GPPW-3, and GPWP-3 \& APRG-5), boat shaped slightly uneven in 5 populations (MGMG-9/11, MGNG-3, MTNU-5, and MTMM-5/7 \& MGMD-3) and boat shaped uneven in 2 populations (NEKP-3 \& KGKP-5). Fewer number of parenchyma cell layers (6-7) underside the midrib was observed in MGMD-3, MGWW-7, NEMR-5 and KGKP-5 populations while the higher number of parenchyma cell layers (11-12) observed only in MTNU-5 and MGMG9/11populations. The rest of the populations possessed 810 layers of parenchyma cells. Underneath the epidermis a lesser number of collenchyma cell layer was observed in populations BDHM-3, MGMD-3 and GPPW-3 while rest of the populations possessed 3-5 collenchyma cell layers. Shape and size of the vascular bundles varied in different populations. Vascular bundle of MGMD-3 and APRG-5 consisted of two crescents like parts separated from few layers of parenchyma cells, while only a single crescent like lower part was observed in NEKP-3 GPWP-3 \& GPPW-3 populations, crescents like lower part and many adaxial vascular bundles observed in NEMR-3 population. Extra vascular bundles in outer part of the main vascular bundle were observed in APRG-5 and GPPW-3 populations. Many Rosette crystals in the phloem were observed in MGMD-3 while it was rare in NEKP-3, MGWW-7, and APRG-5 \&GPPW-3 populations. Further, no rosette crystals were observed in NEMR-3 and MTNU5 populations

Unidentified darkly stained substance was observed in intercellular space of pith and cortex in NEKP-3 GPWP-3 MGWW-7 APRG-5 and MGNG-3 populations. In addition, continuous layer of stone cells just outside the vascular bundle was observed in BDHM-3, NEKP3,MTMM-5/7,MGMG-9/11 and MGNG-3 populations while rest of the populations showed discontinuous layers of stone cells.

Some of the characters such as the presence of unicellular, multicellular and glandular trichomes with varying shapes, single layer of palisade and difference in vascular bundle shape have been described as common characters for family Meliaceae by Metcalfe and Chalk in 1957. However, in the present study, we have observed distinct interpopulational variations in these characters together with many other characters in $M$. pinnata collected from different areas of Sri Lanka.

In Underneath the epidermis, the cortex composed with many layers of parenchyma. The vascular bundle shape varied from oval (BDHM-3, MGMD-3, GPWP-3, NEKP3, MGNG-3 \& GPPW-3) to irregular (MGWW-7 APRG-5, MGMG-9/11 KGKP-5), and triangular (NEMR-3 \&MTMM-5/7) in different populations. Complete vascular bundles were found in all populations bearing 3 
leaflets while incomplete vascular bundles were found in populations bearing more than 3 leaflets. In addition to the main vascular bundle extra vascular bundles were found in cortex region of some populations (NEMR-3, MTMM-5/7, MGMG-9/11, and KGKP-5 \& MGNG-3) irrespective of their number of leaflets. The pith size is varies from small to large consisting of hexagonal or orbicular parenchymatic cells. Diverse pith shapes such as crown shape (MGWW-7, GPWP-3 \&MGMD-3), circular (BDHM-3, NEKP-3, GPPW-3), triangular (NEMR-3 MTMM-5/7), irregular (KGKP-5, MTNU-5), oval in MGNG-3 and star shape in APRG-5 population were recorded. In additions diverse type of secretary cells, druses and cell inclusions were also present in varying frequencies.

According to the previous studies [13], cork of the stem of the family Meliaceae has invariably arisen from the sub epidermis and consists of cells in varying thickness. More over the phloem and xylem constitute closed cylinders. Pith varies in sizes and presence of secretary cells and stone cells is common. Some of the observations are in accordance with this general description. However, according to our observations, xylem and phloem (vascular bundle) of some populations (APRG-5, KGKP-5, MGMG-9/11, MGNG-3, MTMM-5/7 and MTNU-5) are not closed and shapes also varied, especially the vascular bundles of populations APRG-5, KGKP-5 are separated into many parts. In addition we have observed extra vascular bundles in some populations.

The outer surface of the petiole varied from even to uneven nature. Non glandular trichomes were present in all populations, but in varying frequencies. However glandular trichomes were absent in MGWW-7, NEMR-3 \& MTMM-5/7 populations. Shape of the petiole in all populations except GPPW-3, APRG-5 \& NEMR-3 was round. Two projections were found in adaxial surface of the petiole of GPPW-3 population. Adaxial and abaxial epidermal cells of petiole of all populations are approximately equal in size. One to three layers of collenchyma cells are located immediately under the epidermis which is followed by 7-8 layers of parenchyma in APRG-5 \& MTNU-5 and 11-12 layers in NEKP-3, MTMM-5/7, KGKP-5, while rest of the populations except NEMR-3 contained 9-10 layers of parenchyma. However population NEMR-3 possessed 13-14 layers of parenchyma. Heart shaped complete vascular bundle was present in MGMG-9/1, MGNG-3 and MGWW-7 populations while NEMR-3, GPPW-3, MTMM-5/7 possessed triangular incomplete vascular bundles. Rest of the populations contained complete triangular shape vascular bundles. Presence of secretary cells, intercellular inclusions and druses were also observed. Presence of cylindrical or single crescent shaped vascular bundle, various types and sizes of secretary cells and solitary or clustered crystals have been described as common characters of petiole of family Meliaceae [13]. They have also clearly pointed out the necessity of considering further anatomical evidence to verify taxonomic divisions in family Meliaceae. In addition to the common features we noted the presence of triangular incomplete vascular bundle in NEMR-3, MTMM-5/7 and GPPW-3; triangular complete heart shaped vascular bundle in MGNG-3 and MGWW-7 populations.

Unicellular simple, bifurcate, glandular stalked and sessile trichomes were observed. Stomata are present only in lower surface of the leaf. Shape of the epidermal cells of population MGMD-3 was hexagonal while all others are irregular. Epidermal cell number per unit area was much higher in APRG-5 than that in the other population. Moreover sandy crystals were present in population NEMR-3.

\subsection{Cluster Analysis}

In the dendrogram all populations got separated into two major clusters at a distance of about $100 \%$, as these bearing 5 leaflet verses other types. Then APRG-5 has got separated from others at a distance of $50 \%$ which is acceptable as it bears several unique characters such as irregular incomplete vascular bundles in stem, presence of extra vascular bundle in the parenchyma tissues of the midrib, star shaped pith in the petiole and the highest number of epidermal cells in upper epidermis. The second cluster has also got separated into 2 parts as BDHM-3, MGMD-3, and GPPW-3, MGNG-3 and MGMG-9/11in one group and GPWP-3, NEKP-3, MGWW-7and NEMR3 in the other group at the distance of more than $75 \%$.

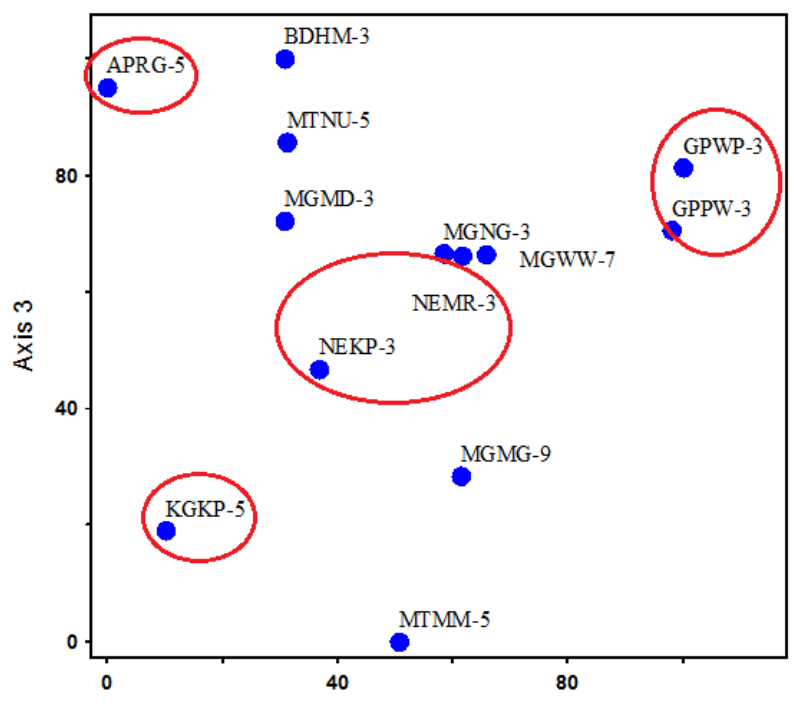

Figure 2. Correspondence analysis on basis of 53 polymorphic anatomical characters of thirteen populations of Munronia pinnata

Further within that cluster NEMR-3 got separated from all the others at a distance of about $60 \%$. Anatomical features of the population NEMR-3 showed crescent like part and several adaxial parts as vascular tissues in midrib, extra vascular bundle in the stem, triangular shaped petiole, vary high number of parenchyma cell layers in the petiole, glandular stalked trichome in lower epidermis and low number of stomatal index.

\section{Conclusions}

Population collected from Ritigala (APRG-5) is distantly related to all others and hence deserve placing in a sub specific taxon of $M$. pinnata. A close relationship was observed in populations collected from Nuwaraeliya, Gampaha and Moneragala districts supporting the idea of existing related individuals in the same geographical area. however, no clear relationship was observed among populations with the same leaflet number. The identification key developed in this study could be used as 
standardized information on the occurrence and distribution of the anatomically differentiated populations of $M$. pinnata in Sri Lanka. Moreover, molecular studies such as isozyme separation or DNA finger printing of these 13 populations are required to decide the taxonomic status of variable M.pinnata populations available in Sri Lanka.

Sequel indented key prepared using anatomical characters to identify 13 populations of Munronia pinnata available in Sri Lanka

1. Stem vascular bundle incomplete...... APRG-5, MTMM5/7, MGMG9/11, MTNU-5, KPKG-5 MGNG-3

2. Midrib outer surface even MGMG9/11, MGNG-3

3. Intercellular space of the midrib pith filled with coloured cell inclusions. MGNG-3

3. Intercellular space of the midrib pith not filled with coloured cell inclusions. MGMG9/11

2. Midrib outer surface uneven ...... APRG-5, MTMM5/7, MTNU-5, KPKG-5

4. Epidermal trichomes present underside only APRG-5

4 Epidermal trichomes on both sides of the midrib........MTMM5/7, KPKG-5 MTNU-5

5. Glandular epidemal trichomes absent in the midrib -KPKG-5

5. Glandular epidermal trichomes present in the midrib - TMM5/7, MTNU-5

6. Petiole contain11-12 parenchymalayers.....MTMM5/7

6. Petiole contain 7-8 parenchyma layers.......MTNU-5

1. Stem vascular bundle complete BDHM-3, MGMD-3, NEKP-3, GPWP-3, MGWW-7, NEMR-3, GPPW-3

7. Outer surface of the petiole even NEMR-3

7. Outer surface of the petiole uneven. BDHM-3, MGMD-3, GPWP-3, MGWW-7, GPPW-3 NEKP-3

8. Thickness of collenchyma in the petiole less than 3 layers. BDHM-3,MGWW-7

9. Secretary cavities present in the petiole pith BDHM-3

9. Secretary cavities absent in the Petiole pith .MGWW-7

8. Thickness of collenchyma in the petiole more than 3 layers...MGMD-3, GPWP-3, GPPW-3 NEKP-3 10. Leaflower epidermal cell margins entire MGMD-3, NEKP-3

11. Shape of the lower epidermal Cells hexagonal MGMD-3

11. Lower epidermal cells not hexagonal.....NEKP-3

10. Leaflower epidermal cell margins not entire......GPWP-3, GPPW-3

12. Small crystals present in the leaf upper epidermis .......GPPW-3

12. Small crystals absent in the leaf upper epidermis GPWP-3 medicinal Plant Munronia pinnata (Wall.) Theob.(Meliaceae) in Sri Lanka. Bangladesh J. Plant. Taxon. 18 (1): 39-49.

\section{References}

[1] Mabberley, 1995. Meliaceae. In: Dassanayake MD, Forsberg F.R. and Clayton WD. eds. A Revised Handbook to the Flora of Ceylon. Vol ix. Amerind Pub. Co. Ltd. New Delhi 230-239.

[2] Jayaweera, B.M.A. 1982. Medicinal plants (indigenous and exotic) used in Ceylon-part (IV). 59 Natn. Sci. Coun. Sri Lanka.

[3] Hooker, J.D, 1872. Flora British India Vol. 2. 542-543 Savills Edwards and Co, Printers, Chandos Street, Covert Garden London.

[4] Dharmadasa, R.M., Hettiarachchi, P.L. and Premakumara, G.A.S. 2011. Geographical distribution and conservation of a rare
[5] Dharmadasa, R.M., Hettiarachchi P.L, and Premakumara G.A.S. 2014. Intraspecific Variation and Taxonomic Delimitation of Munronia pinnata (Meliaceae) in Sri Lanka. World Journal of Agricultural Research 2, No. 1: 26-36.

[6] Pandey, B.P. 1996. Plant anatomy for degree honours and post graduate students. S Chan \& Company Limited, Ram Nagar New Delhi. 461-466,

[7] Adeniyi A. Jayeola.2009. Micromorphological study of plant fragments in some powdered medicinal plants Journal of Medicinal Plants Research Vol. 3(5), 438-442.

[8] Kundu, S.K.,Tierstedt, P.M.A., 1999.Variation in net photosynthesis,stomatal characteristics, leaf area and whole-plant 
phytomass production among ten provenances of neem (Azadiracta indica). Tree Physiol. 19, 47-52.

[9] Stace C 1980. Plant taxonomy and biosystematics. Edward Arnold publisher Ltd, London.

[10] Pennington, T.D. \& Styles, B.T. 1975. A generic monograph of the Meliaceae. Blumea 22: 419-540.

[11] Radford, A. E. Dickson, W. C., Massey, J. R. and Bell, C. R. 1974. Vascular Plant Systematic. Harper and Row Publishers. New York: P 891.

[12] Trease, G.E. and Evans, W.C.2002. Pharmacognosy $15^{\text {th }}$ Edn. Saunders, pp 214-239,

[13] Metcalfe CR, Chalk L. 1957. Anatomy of the Dicotyledons, Systematic Anatomy of the leaf and stem.Vol. I. 2nd Ed. Clarendon Press, Oxford.

[14] Alexandra N. Muellner, Rosabelle Samuel, Mark W. Chase1, Annette Coleman \& Tod F. Stuessy 2008. An evaluation of tribes and generic relationships in Melioideae (Meliaceae) based on nuclear ITS ribosomal DNA. TAXON 57 (1): 98-108.

[15] Ghahreman A, Khatamsaz M, Ganj-Karimi M. 1999. Leaf epidermal studies in the genus Hyoscymus L. (Solanaceae) in Iran. Iran. J. Bot. 8(1): 81-90.

[16] Harms H,1940. Meliaceae. In H. Harms and J. Mattfeld [eds.], Die Natuerlichen Pflanzenfamilien, (2nd ed., 19 bI). 1-172. W. Engelmann, Leipzig, Germany.

[17] Patrick, S. Herendeen \& Regis B. Miller. 2000. Utility of wood anatomical characters in cladistic analyses IAWA Journal, Vol. 21 (3): 247-276.

[18] Shu-Hua Qi, Li Chen, Da-Gang Wu, Yun-Bao Maa and XiaoDong Luoa. 2003. Novel tetranortriterpenoid derivatives from Munronia henryi. Tetrahedron 59: 4193-4199.

[19] Stresburger, E.1866. Ein Beitrag zur Entwicklungsgeschichte der spaltoffnungen, Jahrb. Wiss. Bot. 5: 297-342. 